\title{
IMPLEMENTASI WhatsApp MOBILE LEARNING UNTUK MENINGKATKAN HASIL BELAJAR MAHASISWA POKOK BAHASAN PENGENALAN KOMPONEN ELEKTRONIKA
}

\author{
Hendrik Pratama1, Andista Candra Yusro ${ }^{2}$ \\ ${ }^{1}$ Pendidikan Teknik Elektro, Fakultas Pendidikan Teknologi dan Kejuruan, IKIP PGRI Madiun \\ ${ }^{2}$ Pendidikan Fisika, Fakultas Pendidikan Matematika dan IPA, IKIP PGRI Madiun

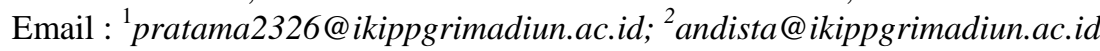

\begin{abstract}
Abstrak
Permasalahan yang muncul dalam penelitian ini yakni kurangnya optimalisasi peran media sosial berbasis android smartphone khususnya WhatsApp Messenger dalam upaya meningkatkan hasil belajar. Peran media sosial lebih banyak digunakan sebagai komunikasi secara online, seperti chatting, pemberitahuan kabar, undangan, hiburan, dan promosi bisnis. Penelitian ini bertujuan untuk mengetahui penerapan Whatsapp Mobile Learning sebagai upaya meningkatkan hasil belajar pada pokok bahasan Konsep Dasar Elektronika. Penelitian yang akan dilakukan menggunakan metode penelitian tindakan kelas (PTK). Tahapan penelitian yang dilakukan meliputi tahap perencanaan, pelaksanaan tindakan, pengamatan, dan refleksi. Subjek penelitian ini adalah 21 mahasiswa SMT gasal tahun akademik 2015/2016 Program Studi Pendidikan Teknik Elektro IKIP PGRI Madiun. Data yang diperoleh berupa hasil dokumentasi, observasi, wawancara, dan tes hasil belajar. Hasil penelitian menyatakan bahwa implementasi whatsapp sebagai mobile learning dapat meningkatkan hasil belajar mahasiswa pada pokok bahasan pengenalan komponen elektronika. Pada siklus I, pertemuan I ketercapaian pembelajaran sebesar $45 \%$ dan meningkat pada pertemuan II menjadi $60 \%$. Pada siklus II, ketercapaian pembelajaran juga meningkat pada pertemuan III menjadi $75 \%$ dan pertemuan IV sebesar $82 \%$. Dalam hal ini I capaian peningkatan hasil belajar mahasiswa melebihi indikator kinerja yaitu $80 \%$ sehingga pembelajaran dikatakan berhasil.
\end{abstract}

Kata kunci: whatsApp, mobile learning, hasil belajar, elektronika

\section{Pendahuluan}

Kondisi pembelajaran di Program Studi Pendidikan Teknik Elektro IKIP PGRI Madiun membutuhkan konsep pembelajaran yang aktif, inovatif, kreatif, efektif, dan menyenangkan. Hal ini didasarkan pada karakteristik materi seperti Elektronika Dasar menuntut mahasiswa menguasai teori sekaligus mampu mengaplikasikannya secara riil.

Hasil wawancara dengan mahasiswa menunjukkan bahwa metode pembelajaran yang dilakukan guru sudah berbasis PAIKEM, disertai praktikum, demonstrasi, dan diskusi. Namun pada mata pelajaran Elektronika Dasar, mahasiswa masih membutuhkan bimbingan lebih diluar jam perkuliahan. Cakupan materi yang luas dengan disertai praktik menuntut mahasiswa untuk selalu berkomunikasi dengan dosen. Hal ini dimaksudkan agar saat menemui kendala, mahasiswa langsung dapat berdiskusi dan memohon bantuan saran.

Hasil evaluasi terhadap mahasiswa Pendidikan Teknik Elektro semester 1 (satu) tahun akademik 2015/2016 menunjukkan bahwa rata-rata hasil belajar pokok bahasan Konsep Dasar Elektronika masih rendah yaitu 66,26 (kriteria cukup) dengan ketercapaian pembelajaran dibawah standar yang diinginkan yaitu $80 \%$. Hasil tes dari 21 mahasiswa terdapat 1 mahasiswa dengan kategori tidak lulus, 17 mahasiswa kategori cukup, dan 3 mahasiswa dengan kategori baik. Data tersebut menunjukkan bahwa proses pembelajaran belum optimal.

Perkembangan

telekomunikasi dan perangkat handphone saat ini sangat pesat. Pendidik dan Peserta didik sudah menggunakan handphone sebagai alat komunikasi, untuk mengirim 
pesan, menerima panggilan, padahal dengan handphone mahasiswa dapat mengakses pelajaran. Sehingga munculah ide mobile learning sebagai salah satu alternatif media pembelajaran dengan memanfaatkan aplikasi WhatsApp. Menurut (Sarrab dkk, 2012) istilah M-Learning atau Mobile Learning merujuk pada penggunaan perangkat genggam seperti PDA, ponsel, laptop dan perangkat teknologi informasi yang banyak digunakan dalam belajar mengajar, dalam hal ini difokuskan pada perangkat handphone (telepon genggam).

Berdasarkan hasil wawancara dengan mahasiswa, 95\% sudah menggunakan Smartphone dengan memanfaatkan aplikasi WhatsApp. Dengan menggunakan perangkat bergerak (handphone), maka program mobile learning diharapkan akan semakin mudah dijangkau dan dimanfaatkan. Amry (2014) menyatakan bahwa dibandingkan pembelajaran konvensional, M-learning memungkinkan adanya lebih banyak kesempatan untuk kolaborasi secara ad hoc dan berinteraksi secara informal di antara pembelajar.

Realita yang terjadi pada mahasiswa menunjukkan bahwa sebagian besar hanya diperuntukkan untuk telepon, SMS dan chatting. Belum banyak yang digunakan untuk pemanfaatan pembelajaran dalam dunia pendidikan. Tantangan yang ada adalah belum banyak pemanfaatan media sosial untuk peningkatan mutu pembelajaran. Evrim Baran (2014) menyatakan bahwa mobile learning menjadi perangkat pembelajaran yang menarik untuk peningkatan mutu pendidikan. Hasil penelitian menunjukkan adanya peningkatan prestasi belajar peserta didik setelah dilakukan pembelajaran dengan mengintegrasikan dengan mobile learning. Selain itu pola penggunaan media sosial yang hanya sebagai hiburan sedikit bergeser ke arah pembelajaran. Dari sisi pendidik sangat membantu dalam fungsi kontrol, motivasi, dan fasilitator.

Tabel 1. Data Hasil Tes pada Siklus I

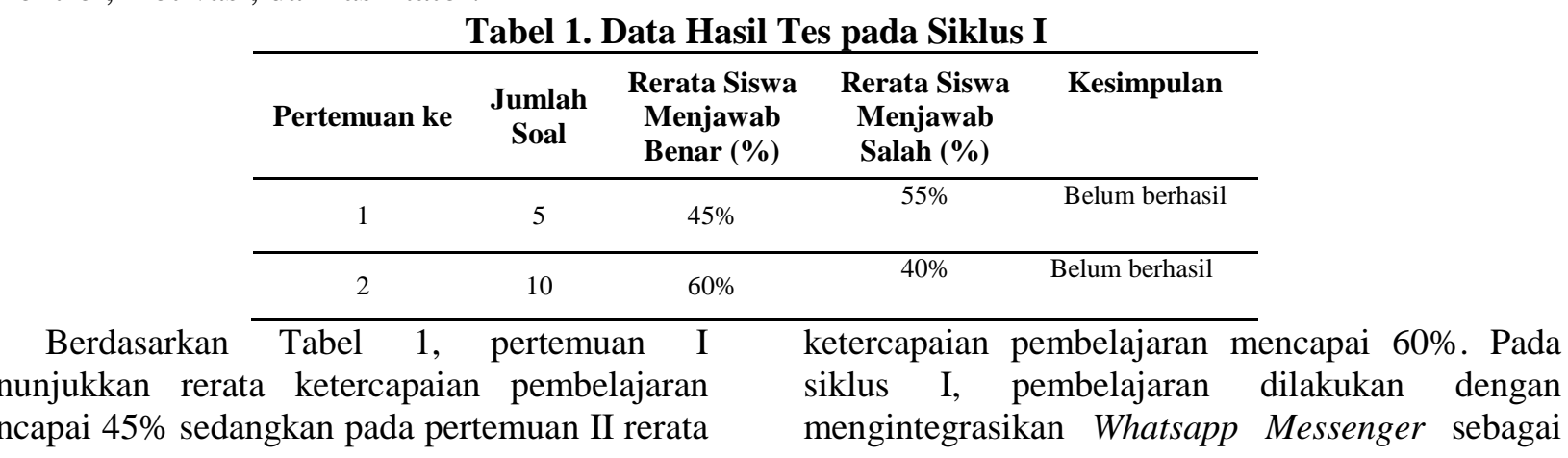

Berdasarkan Tabel 1, pertemuan I menunjukkan rerata ketercapaian pembelajaran mencapai $45 \%$ sedangkan pada pertemuan II rerata
Mengacu pada latar belakang diatas, maka tujuan penelitian ini yaitu untuk mengetahui penerapan Whatsapp Mobile Learning sebagai upaya meningkatkan hasil belajar pada pokok bahasan Konsep Dasar Elektronika.

\section{Metode Penelitian}

Penelitian dilaksanakan di program studi Pendidikan Teknik Elektro IKIP PGRI Madiun pada bulan Oktober tahun 2015. Subyek penelitian ini adalah mahasiswa SMT gasal yang mengambil mata kuliah Elektronika Dasar berjumlah 21 mahasiswa. Teknik pengumpulan data diperoleh dari hasil dokumentasi, observasi, wawancara, dan tes hasil belajar.

Penelitian ini menggunakan model Penelitian Tindakan Kelas (PTK) yang berlangsung dalam 2 siklus, dan pada setiap siklus dilakukan dua kali pertemuan. Setiap siklus terdiri dari langkah-langkah berikut: (1) perencanaan, (2) pelaksanaan tindak pembelajaran, (3) pengamatan terhadap tindak pembelajaran dan dampaknya, serta (4) refleksi terhadap tindak pembelajaran yang telah dilakukan.

Teknik analisis yang digunakan dalam penelitian ini adalah analisis interaktif. Model analisis interaktif mempunyai tiga komponen, yaitu: 1) Reduksi Data (Data Reduction), 2) Penyajian Data (Data Display), 3) Conslucion Drawing(verification). Indikator kinerja dalam penelitian ini adalah capaian peningkatan hasil belajar mahasiswa sebesar $80 \%$.

\section{Hasil Penelitian dan Pembahasan}

Berikut disajikan data dari setiap siklus dan pembahasannya.

\section{Siklus I}

Data tes hasil belajar siklus I pada pertemuan I dan pertemuan II dapat disajikan pada Tabel 1 berikut ini. 
pendukung proses belajar mengajar. Proses pembelajaran dilakukan sebagai berikut:

1) Mahasiswa dibentuk menjadi 5 group dalam aplikasi Whatsapp Messenger dengan spesifikasi materi yang berbeda.

2) Sebelum pembelajaran dikelas dilakukan, mahasiswa diberi permasalahan tentang materi Resistor, Kapasitor, Induktor, Dioda, dan IC dalam bentuk file yang dikirim menggunakan aplikasi Whatsapp Messenger yang dikirim pada masing-masing group.

3) Mahasiswa mempelajari file yang diberikan.

4) Mahasiswa diberi video pembelajaran tentang komponen elektronika untuk meningkatkan pengetahuan dan semangat belajar melalui aplikasi Whatsapp Messenger.

5) Proses pembelajaran dikelas yang dipresentasikan oleh kelompok Resistor dan Kapasitor.

6) Mahasiswa mengerjakan tes untuk mengetahui ketercapaian hasil belajar.

Pada pertemuan II terlihat peningkatan hasil belajar karena proses pembelajaran disertai dengan video. Hal ini mengacu pada pertemuan I bahwa hasil belajar mahasiswa masih rendah walaupun sudah ada perlakuan. Sehingga dengan cepat dosen melakukan tindakan dengan mengirimkan video pembelajaran. Keberadaan aplikasi Whatsapp Messenger sangat mendukung pendidik untuk aktif berkomunikasi dengan group yang dibentuk. Sejalan dengan Barhoumi (2014), salah satu manfaat WhatsApp Messenger yaitu memfasilitasi kolaborasi online antara pendidik dan peserta didik. Semangat belajar mahasiswa meningkat dan lebih tertarik untuk menganalisis materi yang diberikan setelh diberi video. Namun demikian, rerata ketercapaian hasil belajar masih belum mencapai standar yang diinginkan.

Peneliti selanjutnya melakukan analisis dan refleksi. Pada siklus I terindentifikasi yaitu mahasiswa belum terbiasa menggunakan aplikasi Whatsapp Messenger sebagai media belajar, banyak yang tidak peduli dengan pesan singkat yang dikirim guru sebagai bagian dari metode belajar. Maka selanjutnya dilakukan perbaikan pada siklus II.

\section{Siklus II}

Data tes hasil belajar siklus II pada pertemuan III dan pertemuan IV dapat disajikan pada Tabel 2 berikut ini.

Tabel 2. Data Hasil Tes pada Siklus I

\begin{tabular}{ccccc}
\hline $\begin{array}{c}\text { Pertemuan } \\
\text { ke }\end{array}$ & $\begin{array}{c}\text { Jumlah } \\
\text { Soal }\end{array}$ & $\begin{array}{c}\text { Rerata } \\
\text { Siswa } \\
\text { Menjawab } \\
\text { Benar (\%) }\end{array}$ & $\begin{array}{c}\text { Rerata } \\
\text { Siswa } \\
\text { Menjawab } \\
\text { Salah (\%) }\end{array}$ & Kesimpulan \\
\hline 1 & 5 & $75 \%$ & $25 \%$ & $\begin{array}{l}\text { Belum } \\
\text { berhasil }\end{array}$ \\
\hline 2 & 10 & $82 \%$ & $18 \%$ & Berhasil \\
\hline
\end{tabular}

Berdasarkan Tabel 2, pertemuan III menunjukkan rerata ketercapaian pembelajaran mencapai $75 \%$ sedangkan pada pertemuan IV rerata ketercapaian pembelajaran mencapai $82 \%$. Proses pembelajaran sama dengan siklus I. Namun pada siklus II yaitu:

1) Sebelum pembelajaran, mahasiswa mempelajari materi yang dikirim pendidik melalui aplikasi Whatsapp Messenger.

2) Setelah siswa mempelajari, pendidik memberikan kuiz pada masing-masing kelompok yang dikirim melalui aplikasi Whatsapp Messenger.
3) Proses pembelajaran dikelas yang dipresentasikan oleh kelompok Induktor, Dioda, dan IC.

4) Pendidik mengintegrasikan pembelajaran berbasis proyek untuk memberikan variasi pembelajaran.

5) Mahasiswa mengerjakan tes untuk mengetahui ketercapaian hasil belajar.

Pada pertemuan III terlihat ada peningkatan yang signifikan dibandingkan pertemuan II walaupun capaian pembelajaran belum dikatakan berhasil. Namun pada pertemuan IV sudah menunjukkan ketercapaian hasil belajar yaitu $82 \%$ yang melebihi standar ketuntasan yang diberikan. Sehingga pembelajaran dikatakan berhasil. 


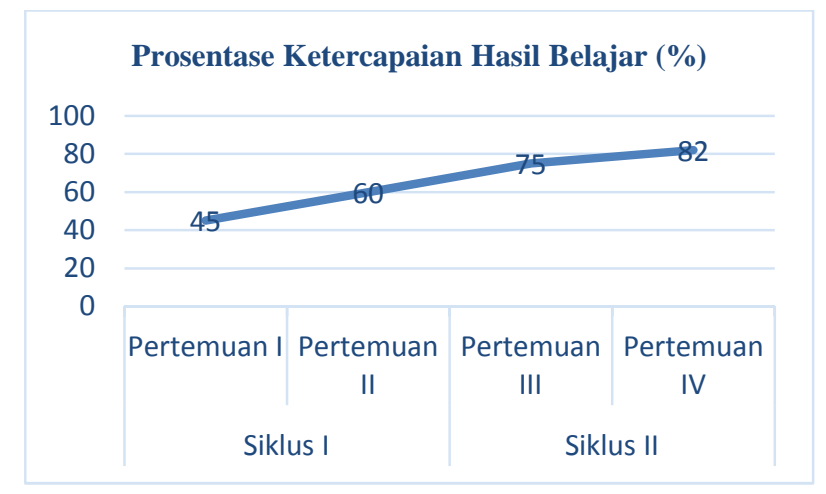

\section{Gambar 1. Grafik Hubungan Ketercapaian Hasil Belajar}

Berdasarkan Gambar 1, grafik menunjukkan selalu ada peningkatan hasil belajar ditiap pertemuan. Pada siklus II pemberian tugas proyek membuat menuntut siswa untuk aktif mencari informasi dan belajar dalam group masing-masing. Contoh proyek mahasiswa dapat dilihat pada Gambar 2. Mahasiswa bebas berkomunikasi, berdiskusi, dan bertanya dengan pendidik sewaktuwaktu jika mengalami kendala menggunakan aplikasi Whatsapp. Menurut Johnson dkk (2014) forum diskusi yang ada di berbagai platform pembelajaran jarak jauh misalnya WhatsApp Messenger harus dimanfaatkan pendidik maupun peserta didik sebaik mungkin. Forum ini memberikan kesempatan peserta didik secara online untuk berkolaborasi dan bekerja sama untuk membangun pengetahuan. Para peneliti di bidang kolaboratif dan kooperatif belajar menganggap forum diskusi menjadi alat efektif untuk pembelajaran.

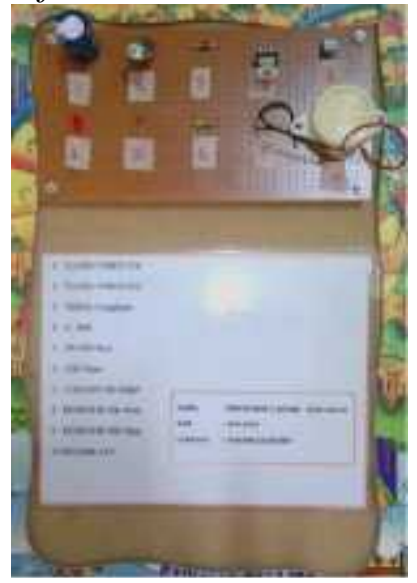

Gambar 2. Contoh Proyek Komponen Elektronika

Pada siklus II, pemberian kuiz pada masingmasing kelompok yang dikirim melalui aplikasi Whatsapp Messenger dilakukan secara bebas dan sewaktu-waktu oleh pendidik. Hal ini dimaksudkan agar siswa selalu siap dan terbiasa menggunakan media sosial seperti Whatsapp sebagai media belajar, bertanggungjawab terhadap tugas dalam kelompok, dan siap dalam mengikuti pembelajaran di kelas. Penelitian Ifeanyi-obi, dkk (2014) menyatakan bahwa media sosial berpengaruh positif pada proses pembelajaran siswa. Proses pengajaran, pelatihan, jaringan, dan kolaborasi antar peserta didik menjadi lebih efektif.

\section{Kesimpulan}

Berdasarkan hasil penelitian, implementasi whatsapp sebagai mobile learning dapat meningkatkan hasil belajar mahasiswa pada pokok bahasan pengenalan komponen elektronika. Pada siklus I, pertemuan I ketercapaian pembelajaran sebesar $45 \%$ dan meningkat pada pertemuan II menjadi $60 \%$. Pada siklus II, ketercapaian pembelajaran juga meningkat pada pertemuan III menjadi $75 \%$ dan pertemuan IV sebesar $82 \%$. Dalam hal ini I capaian peningkatan hasil belajar mahasiswa melebihi indikator kinerja yaitu $80 \%$ sehingga pembelajaran dikatakan berhasil.

Pembelajaran yang terintegrasi WhatsApp Messenger memberikan manfaat pada mahasiswa 
diantaranya yaitu: (1) Informasi dan pengetahuan secara cepat mudah ditransver, (2) kemudahan membuat forum diskusi sehingga media sosial menjadi sarana positif untuk belajar, (3) memfasilitasi kolaborasi tanpa batas antara pendidik dan peserta didik, (4) aplikasi gratis dan mudah digunakan.

\section{Daftar Pustaka}

Amry, A. (2014). The Impact of Whatsapp Mobile Social Learning on the Achievement and Attitudes of Female Students Compared with Face to Face Learning in the Classroom. European Scientific Journal, 10 (22), 116-136.

Baran, E. (2014). A Review of Research on Mobile Learning in Teacher Education. Educational Technology \& Society, 17(4), 17-32.

Barhoumi, C. (2015). The Effectiveness of WhatsApp Mobile Learning Activities Guided by Activity Theory on Students' Knowledge Management. Contemporary Educational Technology Journal, 6 (3), 221238.

CC, Ifeanyi-obi, S. O. Olatunji, and F. Enyindah. "Effects of Blackberry Messenger Usage on the Academic Activities of Agriculture Students in University Of Portharcourt." Age 46: 59-0.

Johnson, Y., dan George D. (2014). The Impact of Whatsapp Messenger Usage on Students Performance in Tertiary Institutions in Ghana. Journal of Education and Practice, 5 (6), 157-164.

Sarrab, M., Elgamel, L. dan Aldabbas, H. (2012). Mobile Learning (M-Learning) and Educational Environments. International Journal of Distributed and Parallel Systems, $3(4), 31-38$. 